\title{
Environment-dependent fitness differences in Drosophila melanogaster: temperature, domestication and the alcohol dehydrogenase locus
}

\author{
Michael J. Kohane and P. A. Parsons
}

Department of Genetics and Human Variation, La Trobe University, Bundoora, 3083, Australia.

(a) Phenotypic fitnesses were estimated over the temperature range $15^{\circ} \mathrm{C}$ to $29^{\circ} \mathrm{C}$ for genotypes at the alcohol dehydrogenase $(A d h)$ locus. The traits measured were egg and larval survival, development time and mating ability in single generation experiments, and total fitness by gene frequency changes in discrete generation populations.

(b) Significant temperature-dependent fitness associations involving the Adh locus were obtained for isofemale strains which had been in the laboratory for eighteen months. Heterozygote advantage was general in the single generation experiments, and in the populations the $A d h F$ allele increased in frequency.

(c) In contrast, populations obtained directly from the field did not show these fitness associations. It was not therefore possible to attribute the genotypic fitness differences detected for the laboratory strains directly to the $A d h$ locus. Indeed, the contrast between the laboratory-adapted and field collected flies may provide a model of likely change under domestication whereby the higher variability of the laboratory strains may be a manifestation of the "stress" involved in the adaptation of populations to laboratory conditions.

(d) The results emphasise the need to commence at the phenotypic level in attempting to understand fitness relationships in natural populations and it is suggested that direct assessments of the effects of environmental stresses of ecological significance may provide an initial strategy.

\section{INTRODUCTION}

This paper attempts to associate genotypic changes at the alcohol dehydrogenase locus $(A d h)$ with phenotypic fitness differences in Drosophila melanogaster. Fitness was measured in single generations by egg and larval survival, development time and mating ability; and total fitness was estimated in discrete generation populations by gene frequency changes (Prout, 1971a, b). We commenced with the premise that the gene is the unit of selection (Clarke, 1975; Dawkins, 1981) so that in certain environments it should be possible to demonstrate direct selection upon alleles at single electrophoretic loci. Since expressed genetic variation for fitness tends to be greater when environmental stresses are extreme (Parsons, 1983), single locus selection should be most apparent in relatively extreme environments. The experiments presented here assess the relations between the common Adh genotypes and phenotypic fitness in the temperature range $15^{\circ} \mathrm{C}$ to $29^{\circ} \mathrm{C}$. Therefore, we commence with a single locus and search, $a$ posteriori, for correlations of adaptive significance. This approach will be contrasted with an a priori approach which beings with the organism, assayed phenotypically in a variety of ways according to circumstances.

The $A d h$ locus is polymorphic in natural populations (van Delden, 1982). The broad and complimentary clines detected on several continents (Johnson and Schaffer, 1973; Malpica and Vassallo, 1980; Oakeshott et al., 1982; David, 1982; Oakeshott, McKechnie and Chambers, 1984) directly or indirectly implicate temperature as a selective agent and hence its choice as a major environmental variable here. The clinal data also possibly indicate that a variable associated with resources, or that a combination of resources and temperature (Malpica and Vassalo, 1980) are involved in the maintenance of the polymorphism. Considering resources, the presumed physiological role of Drosophila ADH in ethanol tolerance and utilisation suggests that ethanol could be an important selective agent. However, evidence from field and laboratory studies is equivocal with respect to this hypothesis (McKenzie and Parsons, 1974; McKenzie and McKechnie, 1978; Hickey and 
McClean, 1980; Oakeshott et al., 1980; Gibson et al., 1981a; van Delden, 1982; McKechnie and Geer, 1984). These results are important since ethanol tolerance can be regarded as an ecological phenotype of clear adaptive significance (Holmes et al., 1980; Parsons, 1983) and also as a metabolic phenotype (Johnson, 1979), presumably controlled by many genes including $A d h$ (McKenzie and Parsons, 1974; Middleton and Kascer, 1983).

An extensive study of the $A d h$ polymorphism in the wine cellar at Chateau Tahbilk, Seymour, Victoria has shown that allele frequency varied with temperature (McKechnie and McKenzie, 1983) and appeared to be independent of ethanol concentration. In fitness studies, McKechnie and McKenzie (1983) found significant variation in female progeny production whereby female heterozygotes produced more progeny. However, there was no indication of relative changes in progeny production among genotypes with changing temperature. McKenzie and McKechnie (1981) did not find differences between the fertilities of the homozygous females and the abilities of the male genotypes to sire progeny. Finally, larval survival and adult longevity at different temperatures and in the presence of ethanol could not be interpreted in terms of fitness differences at the Adh locus for strains derived from Chateau Tahbilk (Ziolo and Parsons, 1982; McKechnie and Morgan, 1982).

Mating appears to be non-random for $A d h$ genotype in the Chateau Tahbilk population-the heterozygote exhibits a higher mating propensity than either homozygote (McKenzie and McKechnie, 1981). A related laboratory study indicated that male heterozygotes mated more frequently with vigin females than did either homozygote (McKenzie and Fegent, 1980). Differences in mating abilities of flies of different $A d h$ genotype have also been detected by Pot et al. (1980) and Knoppien et al. (1980). Finally, heterozygote advantage is a common observation for the Adh locus in a variety of laboratory and field studies (van Delden et al., 1978; Franklin, 1981; van Delden, 1982; Oakeshott, Gibson and Wilson, 1984). There appears to be an association between invididual heterozygosity levels and fitness measured in a number of ways, especially when conditions are stressful (reviewed in Parsons, 1983), suggesting that the heterozygote advantage observed for $A d h$ could be due to stress in contrast to single locus overdominance.

In summary, $A d h$ allele frequencies can be considered to vary with temperature as a "first order" effect by comparison with the other vari- ables cited. In the experiments to be discussed, fitness will be assessed in the range $15^{\circ} \mathrm{C}$ to $29^{\circ} \mathrm{C}$ using (a) 20 isofemale strains derived from Chateau Tahbilk and which had been in laboratory culture for 18 months prior to the experiments, and (b) flies and larvae derived directly from the field from Chateau Tahbilk and Fergusons Vineyard, Yarra Glen, Victoria. The possibility that the extremes of this temperature range are not sufficiently stressful in regard to levels of expressed genetic variation and phenotypic fitness differences is also considered. Further, following Oakeshott, Gibson and Wilson (1984) who have shown that a significant change in $A d h$ allele frequency in response to selection on ethanol media is associated with laboratory populations and not with base populations closely related to nature, the possibility that significant results for the $A d h$ locus are principally detected for laboratory adapted strains is considered. Finally, the contrast between (a) and (b) above permits the possibility of discussing the results in the context of domestication.

\section{MATERIALS AND METHODS}

\section{Laboratory strains}

Ten isofemale strains homozygous for each of $A d h^{F F}$ and $A d h^{S S}$ were obtained from the Genetics Department, Monash University. These strains, were maintained as individual discrete generation populations (half-pint milk bottles) at $25^{\circ} \mathrm{C}$ for eighteen months prior to the experiments. All experiments were conducted at $15^{\circ} \mathrm{C}, 20^{\circ} \mathrm{C}, 25^{\circ} \mathrm{C}$ and $29^{\circ} \mathrm{C}$. The composition of the food was as follows: $2000 \mathrm{ml}$ water, $36 \mathrm{~g}$ agar, $108 \mathrm{~g}$ raw sugar, $72 \mathrm{~g}$ dry yeast, $10.0 \mathrm{ml}$ propionic acid, $24.0 \mathrm{ml}$ nipagen. The vials contained $10.0 \mathrm{ml}$ of food unless otherwise specified, and the population bottles, food to a height of $2 \cdot 5 \mathrm{~cm}$.

Eggs and larvae of the three common Adh genotypes were obtained as follows: The homozygous strains were pooled by transferring 30 virgin adults from each population to a fresh bottle and subculturing this population a number of times. Virgin homozygotes collected from these populations were randomly transferred to empty half-pint milk bottles. Food covered watch-glasses were taped to the mouths of these bottles which were inverted and cultured at $25^{\circ} \mathrm{C}$ for 6 hours for egg laying. At the end of this period the adults were transferred to fresh bottles and watch-glasses and cultured at $25^{\circ} \mathrm{C}$ for a further 6 hours. The adults were then discarded and the watch-glasses were cultured at $25^{\circ} \mathrm{C}$ for 18 hours after which time 
larvae were available. Heterozygous eggs and larvae were obtained from reciprocal crosses of virgin homozygotes as described above. When possible, experiments were conducted with progeny of $A d h F F q \times A d h S S$ 万 $(F S)$ and $A d h S S q \times$ $\operatorname{AdhFF}(S F)$. When this was not possible, the progeny were pooled. Virgin adults of the three common $A d h$ genotypes were derived as follows: Virgin homozygotes were collected as described above and 5 populations were established for each homozygote at $25^{\circ} \mathrm{C}$ by randomly transferring 200 adults to fresh bottles. Experimental virgin homozygotes were collected from these populations every 4 hours. Simultaneously, 5 populations were established at $25^{\circ} \mathrm{C}$ for each reciprocal cross-AdhFF $\% \times A d h S S{ }^{\circ}$ and AdhSS $\uparrow \times$ $A d h F F{ }^{\hat{\sigma}}$ by introducing 150 virgins of each homozygote genotype into a bottle. Experimental virgin heterozygotes were collected from these populations every 4 hours and these were pooled. Virgin adults of each $A d h$ genotype and sex were cultured in vials with no more than 15 flies in a vial, at $25^{\circ} \mathrm{C}$ for 3 days prior to the experiments.

(a) Egg and larval to adult survival and development time

To estimate egg to adult survival and development time 25 eggs of each genotype were transferred to a vial. There were 3 replicates for $A d h^{F S}$ and $A d h^{S F}$ at each temperature. For $A d h^{F F}$ and $A d h^{s S}$, there were 4 replicates at $25^{\circ} \mathrm{C}$ and 5 replicates at the other temperatures. Surviving adults were collected daily.

Larval to adult survival and development time were estimated in independent cultures and competition experiments. In the former, 20 larvae of each genotype were transferred to the same vial and there were 6 replicates at each temperature. Surviving adults were collected daily. In the latter, 20 larvae of each genotype were transferred to the same vial and there were 6 replicates at each temperature. Heterozygotes were obtained from pooled $A d h F S$ and $A d h S F$ larvae. Surviving adults were collected daily and their $A d h$ genotypes were determined by Cellogel electrophoresis.

(b) Mating abilities

The mating abilities of the three common Adh genotypes were estimated for 3 unmated genotypic constitutions as follows: Three-day old virgin adult flies were acclimatised at each temperature for 2 days and were then transferred to half-pint milk bottles containing $0.5 \mathrm{~cm}$ of food which had been acclimatised at each temperature for 6 hours. The unmated genotypic constitutions were denoted $0.25 F, 0.5 F$ and $0.75 F$, representing the $A d h F$ allele frequency among the unmated adults which were in the proportions $10 A d h F F, 30 A d h F S$, 60AdhSS; 30AdhFF, 60AdhFS, 30AdhSS and $60 A d h F F, 30 A d h F S, 10 A d h S S$ respectively. There were 2 replicates at $15^{\circ} \mathrm{C}$ and 3 replicates at the other temperatures. The adults remained together for 150 minutes at $15^{\circ} \mathrm{C}, 60$ minutes at $20^{\circ} \mathrm{C}, 45$ minutes at $25^{\circ} \mathrm{C}$ and 40 minutes at $29^{\circ} \mathrm{C}$. These periods were chosen on the basis of McKenzie (1978). At the end of the mating periods the females were transferred to single vials and the males were discarded following determination of their Adh genotype (Cellogel electrophoresis). The $A d h$ genotypes of the females were determined and for those which mated, 25 of their progeny were scored and the genotype of their mate inferred.

(c) Discrete generation population experiments: Populations were established at each temperature for the above $A d h F$ allele frequencies, denoted $0.25 F, 0.5 F$ and $0.75 F$, by transferring virgin adults in the above genotypic proportions to halfpint milk bottles. The adults were acclimatised at each temperature for 2 days prior to transfer to the bottles which had been acclimatised at each temperature for 6 hours. The adults remained in the bottles for 240 hours at $15^{\circ} \mathrm{C}, 65$ hours at $20^{\circ} \mathrm{C}$, 35 hours at $25^{\circ} \mathrm{C}$ and 30 hours at $29^{\circ} \mathrm{C}$ after which time they were discarded. These periods were chosen on the basis of McKenzie (1978) and ensured that similar egg, larval and adult densities obtained at each temperature. After establishment, the populations were maintained in discrete generations as follows: The subsequent generation was monitored daily and when approximately 350 to 450 adults had emerged, these were transferred to a fresh bottle. These flies remained together for the mating and egg laying periods given above after which time they were removed and the $A d h$ genotypes of 50 adults were determined by Cellogel electrophoresis with the remaining flies being discarded. The populations established at $20^{\circ} \mathrm{C}$ for an initial allele frequency of $0.75 \mathrm{~F}$ were subcultured at generation 13 to $25^{\circ} \mathrm{C}$ and $29^{\circ} \mathrm{C}$. These subcultured populations were maintained for a further 20 generations at $25^{\circ} \mathrm{C}$ and $29^{\circ} \mathrm{C}$.

\section{Field derived flies and larvae}

Approximately $2000 \mathrm{D}$. melanogaster adults were collected at two vineyards, Chateau Tahbilk and Fergusons, by sweeping with a net over a pile of grape refuse during March, 1981 and were divided into two lots of 1000 flies. One lot was used to generate experimental larvae and adults as follows: Adults from each site were randomly assigned to 
three lots of approximately 330 flies and transferred to empty half-pint milk bottles. Food covered watch-glasses were taped to the mouths of the bottles which were inverted and cultured at $25^{\circ} \mathrm{C}$ for 6 hours. The adults were then transferred to half-pint milk bottles containing $2.5 \mathrm{~cm}$ of food at $25^{\circ} \mathrm{C}$ for 5 days after which time they were discarded. Larvae were collected from the watch-glasses following a further 18 hours culture at $25^{\circ} \mathrm{C}$ and virgin adults for the mating experiment were collected at 4 hourly intervals from the above population bottles. The virgin adults were held in vials ( 15 adults per vial) at $25^{\circ} \mathrm{C}$ for 3 days prior to the experiment. The second lot of 1000 flies were used to initiate populations by equally distributing them among 3 population bottles denoted $A, B$ and $C$ for Chateau Tahbilk and Fergusons respectively. Following a 5-day egg laying period at $25^{\circ} \mathrm{C}$ the adults were transferred to fresh bottles and this procedure was repeated until populations derived from each founding population were available for each temperature. These populations were randomly assigned to each temperature as they became available.

(a) Larval to adult survival and development time: To measure larval to adult survival and development time 75 larvae were transferred to a single vial. There were 6 replicates for each site and temperature. Surviving adults were collected daily and their $A d h$ genotypes were determined by $\mathrm{Cel}-$ logel electrophoresis. To obtain an estimate of the expected genotypic frequencies at each site, fewer larvae (25) were cultured in more food $(16.5 \mathrm{ml})$ at $25^{\circ} \mathrm{C}$. There were 8 replicates for each site and these were denoted "controls".

(b) Mating abilities:

The mating abilities of the common Adh genotypes were estimated at $15^{\circ} \mathrm{C}, 20^{\circ} \mathrm{C}, 25^{\circ} \mathrm{C}$ and $29^{\circ} \mathrm{C}$ for flies derived from Chateau Tahbilk only as follows:

30 five-day old virgin males and 30 five-day old virgin females were transferred to half-pint milk bottles containing $0.25 \mathrm{~cm}$ of food. The virgin flies were acclimatised at each experimental temperature for 3 days.prior to transfer to the bottles which had been acclimatised at each temperature for 6 hours. The flies remained together for the specific mating periods described for the laboratory strains and there were 3 replicates at each temperature. At the end of the mating periods the females were transferred to single vials and the males were discarded following determination of their $A d h$ genotype (Cellogel electrophoresis). The $A d h$ genotypes of the females were determined and for those which mated, the genotypes of 25 of their progeny were determined and the genotype of their mate inferred.

(c) Discrete generation population experiments: Populations established for each founding generation and site were randomly assigned to each temperature. The populations were maintained as discrete generations in the manner of the laboratory populations. At particular generations, including the founding one, approximately 100 flies were set aside and their $A d h$ genotypes were determined by Cellogel electrophoresis.

\section{RESULTS}

\section{Laboratory adapted strains}

(a) Egg and larval survival and development time Table 1 gives the results for egg and larval survival of the $A d h$ genotypes in independent culture and competition experiments. Temperature was a significant factor in each experiment-more flies survived at $20^{\circ} \mathrm{C}$ and $25^{\circ} \mathrm{C}$ compared with $15^{\circ} \mathrm{C}$ and $29^{\circ} \mathrm{C}$ suggesting an extreme environment effect. There also appeared to be a greater temperature effect for larval survival in the competition experiment. The approximate orders for increasing genotypic survival were as follows:

egg to adult survival, independent culture:

$$
F F=F S>S F=S S
$$

larval to adult survival, independent culture:

$$
F S=S F \geqq F F \geqq S S
$$

larval to adult survival, competition experiment:

$$
F S>F F>S S \text {. }
$$

Table 2 gives the results for development time, expressed as $T 1 / 2$, the time taken for half of the surviving adults to emerge. Mean $T 1 / 2$ values at each temperature and ANOVAs are shown. Temperature was a significant factor with the characteristic and expected result of more rapid development as temperature increased. The approximate genotypic orders for more rapid development time were as follows:

egg to adult development time, independent culture:

$$
F F=F S<S S=S F
$$

larval to adult development time, independent culture:

$$
F F=S F<F S=S S
$$


Table 1 The Egg and larval to adult survivals of the three common $A d h$ genotypes estimated at $15^{\circ} \mathrm{C}, 20^{\circ} \mathrm{C}, 25^{\circ} \mathrm{C}$ and $29^{\circ} \mathrm{C}$ for eggs and larvae obtained from isofemale strains which had been in laboratory culture for 18 months prior to the experiments

(a) The Egg to adult survival of the common Adh genotypes estimated in independent culture, where 25 eggs of each genotype were cultured in a single vial. Heterozygotes were derived from the progeny of reciprocal homozygote crosses- $A d h^{F S}$ and $A d h^{S F}$.

(i) Means

(ii) ANOVA

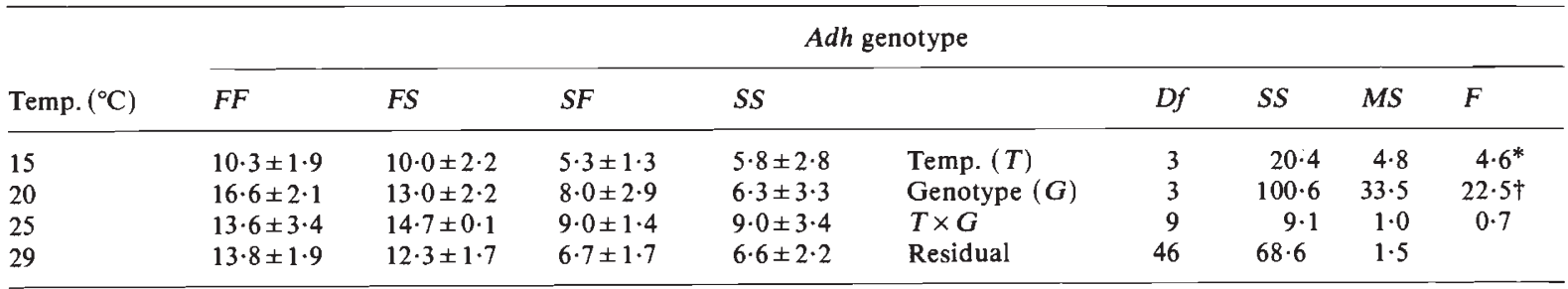

(b) The Larval to adult survivals of the common Adh genotypes estimated in independent culture, where 20 larvae of each genotype were cultured in a single vial. Heterozygotes were derived from the progeny of reciprocal homozygote crosses-Adh ${ }^{F S}$ and $A d h^{S F}$.

(i) Means

(ii) ANOVA

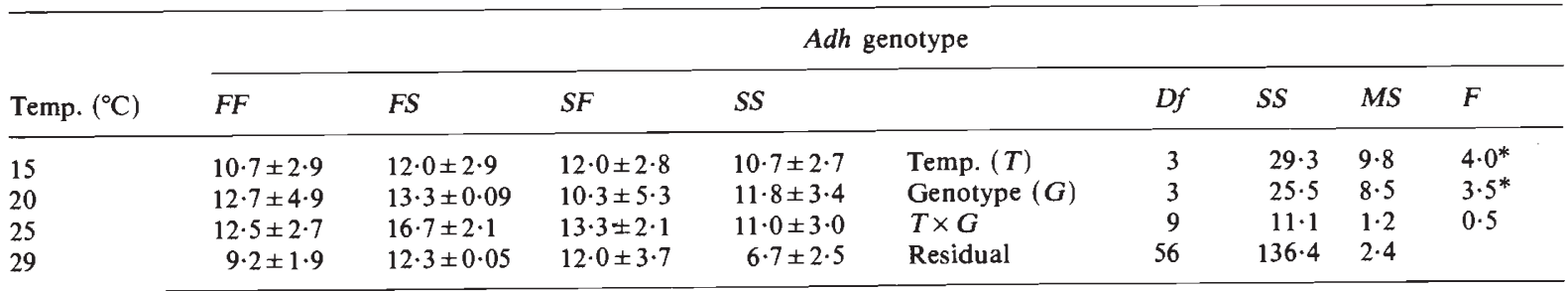

(c) The Larval to adult survivals of the common Adh genotypes estimated in competition experiments, where 25 larvae of each genotype were cultured in the same vial. Heterozygotes were derived from the pooled progeny of reciprocal homozygote crosses$A d h^{F S}$.

(i) Means

(ii) ANOVA

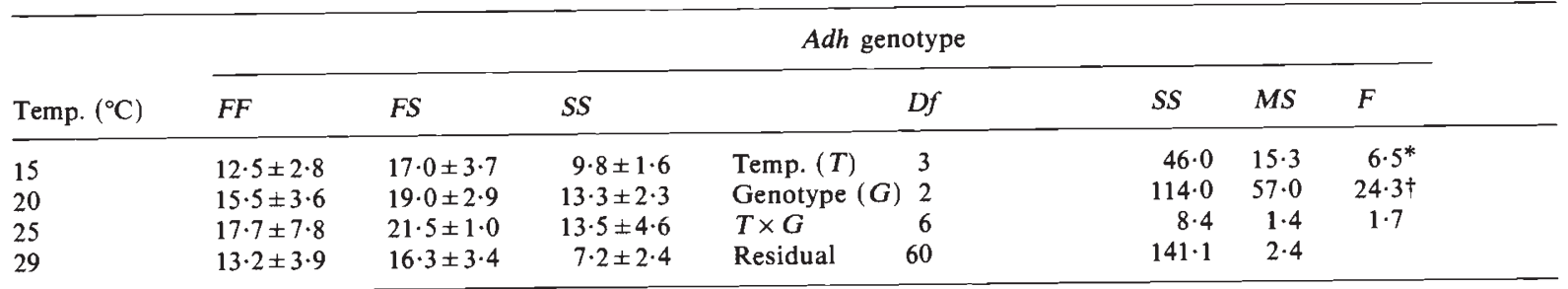

$* p<0.025$

$\dagger p<0.005$

larval to adult development time, competition experiment:

$$
F F=F S<S S .
$$

The significant temperature genotype interaction detected in the competition experiment is indicated by comparisons of the means in table 2 . $A d h S S$ developed slowest at all temperatures, and whilst $A d h F F$ and $A d h F S$ were similar at $15^{\circ} \mathrm{C}$ and $29^{\circ} \mathrm{C}, A d h F F$ developed more rapidly at $20^{\circ} \mathrm{C}$ and $A d h F S$ more rapidly at $25^{\circ} \mathrm{C}$.

(b) Mating abilities

The numbers of males and females of each genotype which mated are given in table 3 for pooled replicates at each temperature. The respective $\chi_{2}^{2}$ values for comparisons between these observed values and expected values based upon the unmated genotypic proportions are also shown. Such comparisons should indicate genotypic differences in mating abilities since in no circumstance did all flies mate, although there were relatively more matings for the initial frequencies $0.25 \mathrm{~F}$ and $0.75 \mathrm{~F}$ and at $29^{\circ} \mathrm{C}$.

Considering the initial $A d h F$ allele frequency of $0 \cdot 25 F$ (table $3(\mathrm{a})$ ), there were no significant $\chi_{2}^{2}$ values indicating that the genotypes of both sexes mated in the same proportions as found in the unmated populations. For $0.5 F$ (table $3(\mathrm{~b})$ ) there were significant $\chi_{2}^{2}$ values for the females at $25^{\circ} \mathrm{C}$ 
Table 2 The egg and larval to adult development times of the three common Adh genotypes estimated at $15^{\circ} \mathrm{C}, 20^{\circ} \mathrm{C}, 25^{\circ} \mathrm{C}$ and $29^{\circ} \mathrm{C}$ for eggs and larvae obtained from isofemale strains which had been in laboratory culture for 18 months prior to the experiments. Development time is expressed as $T 1 / 2$ in days

(a) The egg to adult development time of the common Adh genotypes estimated in independent culture, where 25 eggs of each genotype were cultured in a single vial. Heterozygotes were derived from the progeny of reciprocal homozygote crosses-Adh ${ }^{F S}$ and $A d h^{S F}$.

(i) Means

(ii) ANOVA

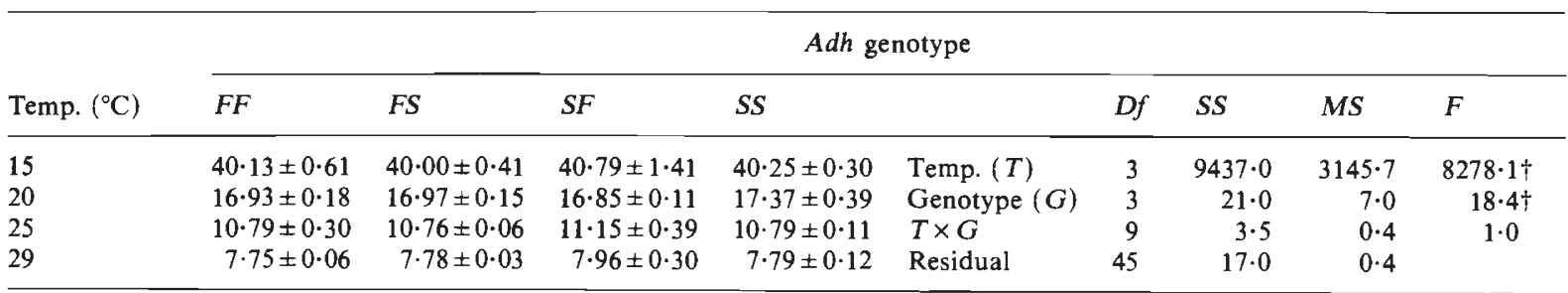

(b) The larval to adult development times of the common Adh genotypes estimated in independent culture, where 20 larvae of each genotype were cultured in a single vial. Heterozygotes were derived from the progeny of reciprocal homozygote crosses- $A d h^{F S}$ and $A d h^{S F}$.

(i) Means

(ii) ANOVA

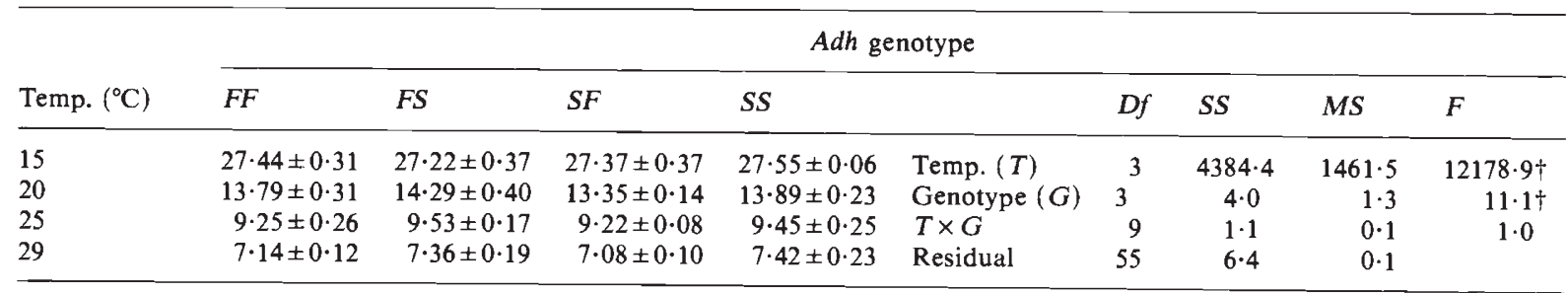

(c) The larval to adult development times of the common $A d h$ genotypes estimated in competition experiments, where 25 larvae of each genotype were cultured in the same vial. Heterozygotes were derived from the pooled progeny of reciprocal crosses-Adh ${ }^{F S}$. (i) Means

(ii) ANOVA

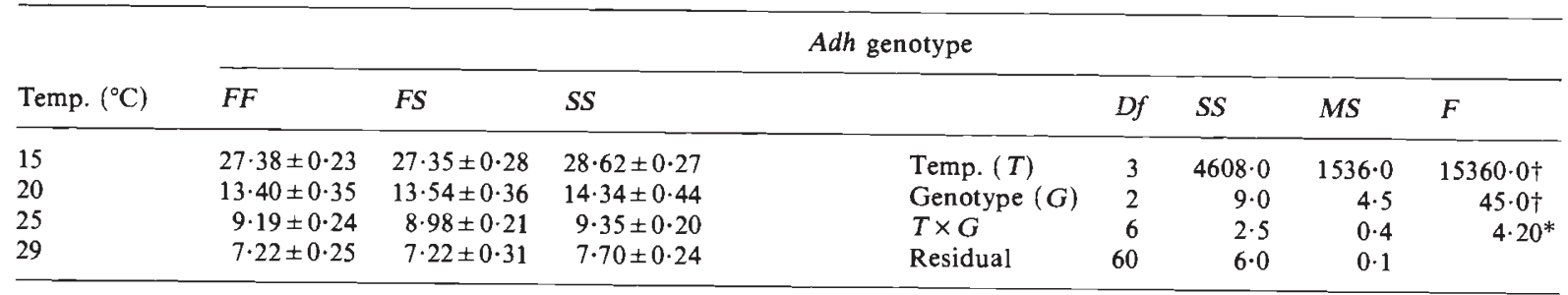

* $P<0.025$.

$+P<0.005$.

and $29^{\circ} \mathrm{C}$ where there was a relative excess of heterozygotes. Considering the homozygotes, they were similar at $25^{\circ} \mathrm{C}$ whilst at $29^{\circ} \mathrm{C}$ there was a relative deficiency of $A d h S S$. For males there was a relative excess of heterozygotes at all temperatures especially at $29^{\circ} \mathrm{C}$, and this was significant at $20^{\circ} \mathrm{C}, 25^{\circ} \mathrm{C}$ and $29^{\circ} \mathrm{C}$, but not at $15^{\circ} \mathrm{C}$. The homozygotes performed similarly at all temperatures. For $0.75 F$ (table $3(\mathrm{c})$ ) there were no significant $\chi_{2}^{2}$ values for the females, and for the males there was a significant excess of heterozygotes and a relative deficiency of $A d h S S$ at $29^{\circ} \mathrm{C}$. In summary, whenever there was a significant departure from the expected values, this was associated with an excess of heterozygotes which appeared greatest at $29^{\circ} \mathrm{C}$, and was especially evident for males. The relative performances of the homozygotes were less consistent.

The effect of temperature variation in determining the number of genotypes of each sex which mated was assessed by $\chi^{2}$ tests of independence for genotype and temperature for pooled replicates at each initial $A d h F$ allele frequency. For the males, no value was significant $\left(0 \cdot 25 F, \chi_{6}^{2}=1 \cdot 26\right.$; $\left.0.5 F, \chi_{6}^{2}=8 \cdot 93 ; 0.75 F, \chi_{6}^{2}=3 \cdot 61\right)$. For the females there was a significant value for $0.5 F\left(0.25 F, \chi_{6}^{2}=\right.$ $\left.3 \cdot 84 ; 0.5 F, \chi_{6}^{2}=14 \cdot 30, p<0 \cdot 05 ; 0.75 F, \chi_{6}^{2}=2 \cdot 24\right)$ where a relative excess of heterozygotes was observed at $25^{\circ} \mathrm{C}$ and $29^{\circ} \mathrm{C}$. These results thus reflect those given in Table 3 and discussed above. 
Table 3 The numbers of males and females of each $A d h$ genotype which mated in the experiments which assessed the mating abilities of flies differing in $A d h$ genotypes. Observed values are shown for pooled replicates at each temperature $\left(15^{\circ} \mathrm{C}, 20^{\circ} \mathrm{C}, 25^{\circ} \mathrm{C}\right.$ and $\left.29^{\circ} \mathrm{C}\right)$ and for each initial $A d h F$ allele frequency $(0.25 F, 0.5 F, 0.75 F) . \chi^{2}$ values for comparisons between observed values and expected values, based upon the unmated genotypic proportions are given

(a) $0.25 F$ initial $A d h F$ allele frequency

(b) $0.5 F$ initial $A d h F$ allele frequency

(c) $0.75 F$ initial $A d h F$ allele frequency

\begin{tabular}{|c|c|c|c|c|c|c|c|c|c|}
\hline \multirow{2}{*}{$\begin{array}{l}\text { Initial } A d h F \\
\text { allele } \\
\text { frequency }\end{array}$} & \multirow[b]{2}{*}{$\begin{array}{l}\text { Temp. } \\
\left({ }^{\circ} \mathrm{C}\right)\end{array}$} & \multicolumn{4}{|c|}{ Female genotype } & \multicolumn{4}{|c|}{ Male genotype } \\
\hline & & $F F$ & $F S$ & $S S$ & Total & $F F$ & $F S$ & $S S$ & Total \\
\hline \multirow[t]{4}{*}{ (a) $0.25 F$} & 15 & 6 & 13 & 31 & $\begin{array}{c}50 \\
\chi_{2}^{2}=0 \cdot 50\end{array}$ & 5 & 18 & 27 & $\begin{array}{c}50 \\
\chi_{2}^{2}=0.90\end{array}$ \\
\hline & 20 & 6 & 18 & 20 & $\chi_{2}^{2}=34.88$ & 3 & 17 & 24 & $\chi_{2}^{2}=1 \cdot 76$ \\
\hline & 25 & 7 & 25 & 39 & $\chi_{2}^{2}=0.91$ & 9 & 26 & 36 & $\chi_{2}^{2}=2.57$ \\
\hline & 29 & 9 & 25 & 50 & $\begin{array}{c}84 \\
\chi_{2}^{2}=0.04\end{array}$ & 10 & 29 & 45 & $\chi_{2}^{2}=1 \cdot 36$ \\
\hline \multirow[t]{4}{*}{ (b) $0.5 F$} & 15 & 33 & 53 & 30 & $\chi_{2}^{2}=1.01$ & 26 & 62 & 28 & $\begin{array}{c}116 \\
\chi_{2}^{2}=0.62\end{array}$ \\
\hline & 20 & 29 & 56 & 32 & $\chi_{2}^{2}=0.37$ & 22 & 75 & 20 & $\begin{array}{c}117 \\
\chi_{2}^{2}=9 \cdot 38 t\end{array}$ \\
\hline & 25 & 23 & 74 & 21 & $\begin{array}{c}118 \\
\chi_{2}^{2}=7 \cdot 69^{*}\end{array}$ & 24 & 75 & 19 & $\begin{array}{c}118 \\
\chi_{2}^{2}=9 \cdot 11^{*}\end{array}$ \\
\hline & 29 & 26 & 69 & 15 & $\chi_{2}^{2}=9 \cdot 32 \dagger$ & 15 & 79 & 16 & $\begin{array}{c}110 \\
\chi_{2}^{2}=20 \cdot 62 \ddagger\end{array}$ \\
\hline \multirow[t]{4}{*}{ (c) $0.75 F$} & 15 & 72 & 24 & 8 & $\chi_{2}^{2}=3 \cdot 69$ & 55 & 41 & 8 & $\begin{array}{c}104 \\
\chi_{2}^{2}=4 \cdot 51\end{array}$ \\
\hline & 20 & 83 & 38 & 12 & $\begin{array}{c}133 \\
\chi_{2}^{2}=0.35\end{array}$ & 76 & 48 & 9 & $\begin{array}{c}133 \\
\chi_{2}^{2}=3 \cdot 21\end{array}$ \\
\hline & 25 & 84 & 32 & 14 & $\chi_{2}^{2}=2 \cdot 80$ & 74 & 43 & 13 & $\begin{array}{c}130 \\
\chi_{2}^{2}=0.62\end{array}$ \\
\hline & 29 & 80 & 30 & 14 & $\chi_{2}^{2}=1 \cdot 94$ & 69 & 49 & 6 & $\begin{array}{c}124 \\
\chi_{2}^{2}=7 \cdot 43^{*}\end{array}$ \\
\hline
\end{tabular}

${ }^{*} P<0.025$.

$+P<0.01$.

$\ddagger P<0.005$.

(c) Discrete generation population experiments

The results for the discrete generation population experiments are given in figs. 1 to 5 expressed as $A d h F$ allele frequencies. For these data, $t$-tests were carried out between the initial and final generations sampled, which was considered a satisfactory procedure since the experiments measured change in $A d h F$ allele frequency in response to population culture at a constant temperature. Further, except for all initial allele frequencies at $15^{\circ} \mathrm{C}$ and for $0.25 \mathrm{~F}$ and $0.75 \mathrm{~F}$ at $29^{\circ} \mathrm{C}$, the number of generations monitored exceeded 29 . Thus it is reasonable to assume that an equilibrium was being approached in the latter populations. Considering the exceptions, the discussion below indicates that significant changes were observed for all initial allele frequencies at $15^{\circ} \mathrm{C}$ and for $0.75 \mathrm{~F}$ at $29^{\circ} \mathrm{C}$. Thus, the only temperature-initial allele frequency combination for which such an assessment may require qualification is $29^{\circ} \mathrm{C}, 0 \cdot 25 \mathrm{~F}$. An overall summary is given in table 4 .

Considering temperature, at $15^{\circ} \mathrm{C}$, significant increases in $A d h F$ allele frequency were observed for all initial allele frequencies. However, it must be noted that for $0.75 F, A d h F$ allele frequency initially decreased for the first four generations and subsequently increased. At $20^{\circ} \mathrm{C}, A d h F$ allele frequency significantly increased for $0.5 F$ and did not change for all other initial frequencies. At $25^{\circ} \mathrm{C}$, $A d h F$ allele frequency significantly increased for $0.75 \mathrm{~F}$ and did not significantly change for all other initial frequencies including the $20^{\circ} \mathrm{C}, 0.75 \mathrm{~F}$ 


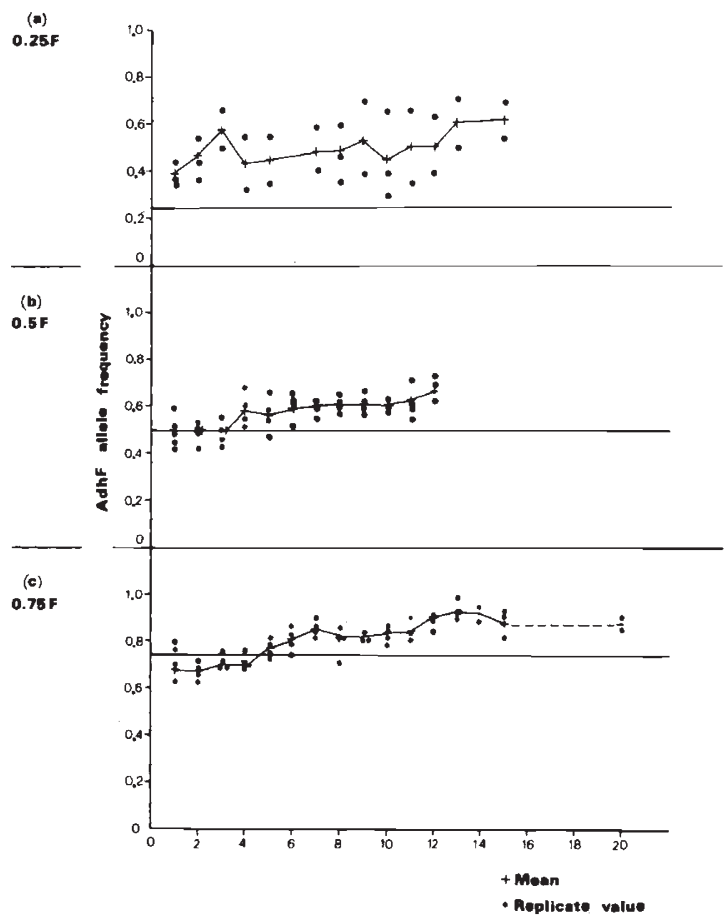

Figure 1 Discrete generation population cage experiments conducted with flies derived from isofemale strains which had been in laboratory culture for 18 months prior to the experiments. The change in $A d h^{F}$ allele frequency observed at $15^{\circ} \mathrm{C}$ for the initial allele frequencies $0.25 \mathrm{~F}$ (a), $0.5 F$ (b) and $0.75 F$ (c). Values are given for each generation sampled and each replicate. Mean values at each generation sampled are also shown.

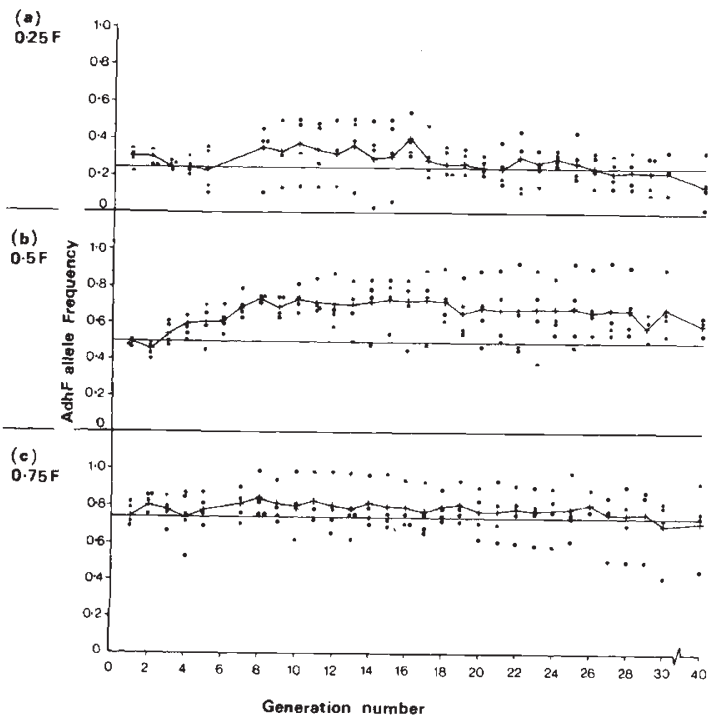

Figure 2 Laboratory strains, discrete generation population experiments: The change in $A d h^{F}$ allele frequency observed at $20^{\circ} \mathrm{C}$ for the initial $A d h F$ allele frequencies of $0.25 F(\mathrm{a}), 0.5 F(\mathrm{~b})$ and $0.75 F(\mathrm{c})$. Details are given in fig. 1.

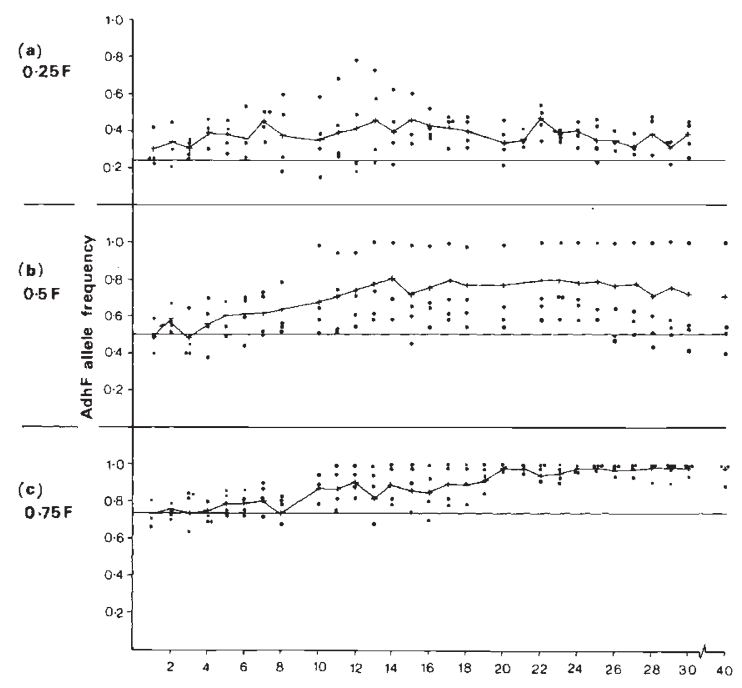

Figure 3 Laboratory strains, discrete generation population experiments: The change in $A d h F$ allele frequency at $25^{\circ} \mathrm{C}$ for the initial $A d h F$ allele frequencies of $0.25 F(a), 0.5 F$ (b) and $0.75 F(c)$. Details are given in fig. 1.

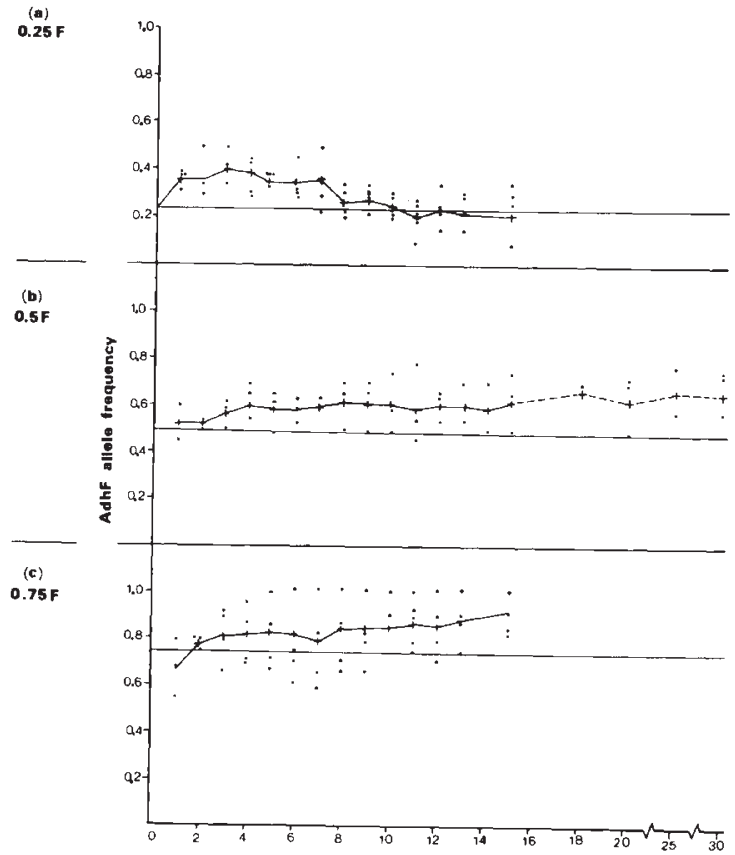

Figure 4 Laboratory strains, discrete generation population experiments: The change in $A d h F$ allele frequency at $29^{\circ} \mathrm{C}$ for the initial $A d h F$ allele frequencies of $0.25 F(\mathrm{a}), 0.5 F$ (b) and $0.75 F(c)$. Details are given in fig. 1. 


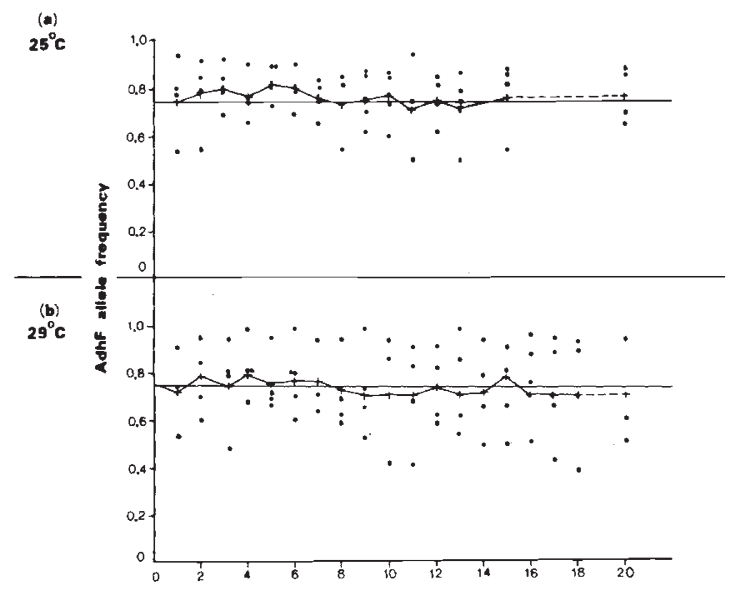

Figure 5 Laboratory strains, discrete generation population experiments: The change in $A d h F$ allele frequency in the populations which were established at $20^{\circ} \mathrm{C}$ for an initial Adh $F$ allele frequency of $0.75 F$ and then subcultured to $25^{\circ} \mathrm{C} \mathrm{(a)} \mathrm{and} 29^{\circ} \mathrm{C}(\mathrm{b})$.

Table 4 A summary of the discrete generation population cage experiments conducted with flies derived from isofemale strains which had been in laboratory culture for 18 months prior to the experiments (figs. 1 to 5). Comparisons have been made between the initial and final generation sampled for $A d h^{F}$ allele frequency. Means and standard errors have been assessed in both two-sided and one-sided $t$-tests. + represents a significant increase in $A d h^{F}$ allele frequency and $n c$, no change in allele frequency.

\begin{tabular}{lcccc}
\hline & \multicolumn{4}{c}{ Temp. $\left({ }^{\circ} \mathrm{C}\right)$} \\
\cline { 2 - 5 } $\begin{array}{l}\text { Initial } A d h^{F} \\
\text { allele frequency }\end{array}$ & 15 & 20 & 25 & 29 \\
\hline $0.25 F$ & $+^{*}$ & $n c$ & $n c$ & $n c$ \\
$0.5 F$ & $+\dagger$ & $+^{*}$ & $n c$ & $n c$ \\
$0.75 F$ & $+^{*}$ & $n c$ & $+\dagger$ & $+^{*}$ \\
$0.75 F$ subcultured & & & & \\
$\quad$ populations & & & $n c$ & $n c$ \\
\hline
\end{tabular}

(i) two-sided $t$-test ${ }^{*} p<0.05$

(ii) one-sided $t$-test; $A d h^{F}$ allele frequency significantly increased at $25^{\circ} \mathrm{C}$ for $0.25 \mathrm{~F}$ and at $29^{\circ} \mathrm{C}$ for $0.5 \mathrm{~F}(p<0.05)$.

populations which were subcultured to $25^{\circ} \mathrm{C}$. As noted in table 4 , for a one-sided test there was a significant increase for $0 \cdot 25 \mathrm{~F}$. At $29^{\circ} \mathrm{C}, A d h F$ allele frequency significantly increased for $0.75 F$ and did not change for $0.25 F, 0.5 F$ and the subcultured populations. It must be noted that for $0.25 F$, the allele frequency initially increased and subsequently decreased to a mean value similar to the initial frequency. Again, for a one-side test $A d h F$ allele frequency significantly increased for $0.5 F$.
Finally, $\chi_{1}^{2}$ comparisons between the observed numbers of $A d h$ genotypes and expected numbers assuming Hardy-Weinberg proportions for each replicate indicated that only two values were significant $\left(0.25 F, 15^{\circ} \mathrm{C}\right.$, replicate $2, \chi_{1}^{2}=3.99, P<$ $0.05 ; 0.25 F, 29^{\circ} \mathrm{C}$, replicate $\left.1, \chi_{1}^{2}=4.41, p<0.05\right)$. A relative excess of heterozygotes was detected in both populations possibly indicating an extreme environment effect.

\section{Field derived flies and larvae}

(a) Larval to adult survival and development time It was not intended nor was it possible to manipulate the input genotypic proportions in this experiment. Thus, survival differences among genotypes can only be detected by comparisons between the results for the controls and the results at each temperature if significantly more flies survive in the former. The controls represent the situation where larvae were cultured in optimum conditions, defined as 25 larvae in $16.5 \mathrm{ml}$ of food at $25^{\circ} \mathrm{C}$. For Chateau Tahbilk, significantly more flies survived in the controls compared with each temperature $(p<0.005)$. However, for Fergusons, significantly more flies survived in the controls compared with $15^{\circ} \mathrm{C}$ and $20^{\circ} \mathrm{C}(p<0.005)$ and $29^{\circ} \mathrm{C}$ $(p<0.05)$ but not for $25^{\circ} \mathrm{C}(p>0.10)$. Thus, since survival was relatively similar in the controls compared with each temperature, the possibility of detecting genotypic differences for larval survival and development time may be less in the Fergusons data.

Table 5 gives the results for genotypic larval survival for the controls and the two sites at each temperature. Pooled replicates are shown. $\chi_{2}^{2}$ values for comparisons between the controls and the experimental values and the $A d h F$ allele frequency in each case are also given. No $\chi_{2}^{2}$ value was significant indicating that the genotypes survived in similar proportions as observed in the controls at each temperature and for each site.

The results for larval development time, expressed as $T 1 / 2$, are given in table 6 , and indicate that the only significant factor was temperature. Therefore, no significant differences between Adh genotypes could be detected at any temperature for larval survival and development time when these fitness components were estimated in competition experiments using field derived larvae. The $A d h F$ allele frequency in these experiments was approximately $0 \cdot 67$. However, temperature variation did affect these fitness components-more flies survived at $20^{\circ} \mathrm{C}$ and $25^{\circ} \mathrm{C}$ compared with $15^{\circ} \mathrm{C}$ and $29^{\circ} \mathrm{C}$. 
Table 5 The larval to adult survival of the common $A d h$ genotypes estimated for larvae obtained as progeny of flies collected at two field sites, the Chateau Tahbilk and Fergusons vineyards. The control represents the case where larvae were cultured in optimum conditions, defined as 25 larvae in $16.5 \mathrm{ml}$ of food at $25^{\circ} \mathrm{C}$. Pooled values are given, and $\chi_{2}^{2}$ comparisons between the respective control values and each experimental temperature are shown. The $A d h^{F}$ allele frequencies in each case are also given for pooled replicates

\begin{tabular}{|c|c|c|c|c|c|c|c|c|c|c|c|c|}
\hline \multirow[b]{2}{*}{ Temp. $\left({ }^{\circ} \mathrm{C}\right)$} & \multicolumn{6}{|c|}{ Chateau Tahbilk } & \multicolumn{6}{|c|}{ Fergusons } \\
\hline & $A d h^{F}$ & $F F$ & $F S$ & $S S$ & Total & $\chi_{2}^{2}$ & $A d h^{F}$ & $F F$ & $F S$ & $S S$ & Total & $\chi_{2}^{2}$ \\
\hline \multicolumn{13}{|l|}{ control } \\
\hline 25 & 0.68 & 79 & 83 & 14 & 176 & & 0.65 & 75 & 74 & 23 & 172 & \\
\hline 15 & 0.67 & 150 & 148 & 34 & 332 & $2 \cdot 22$ & 0.63 & 113 & 137 & 40 & 290 & $3 \cdot 19$ \\
\hline 20 & 0.66 & 150 & 167 & 36 & 353 & $2 \cdot 82$ & 0.69 & 162 & 147 & 30 & 339 & $5 \cdot 63$ \\
\hline 25 & 0.67 & 143 & 179 & 20 & 342 & 4.63 & 0.67 & 164 & 171 & 39 & 374 & $2 \cdot 32$ \\
\hline 29 & $0 \cdot 70$ & 155 & 132 & 30 & 317 & $3 \cdot 61$ & 0.67 & 156 & 145 & 40 & 341 & 0.63 \\
\hline
\end{tabular}

Table 6 The Larval to adult development times of the common Adh genotypes estimated for larvae obtained as progeny of flies collected at two field sites, the Chateau Tahbilk and Fergusons vineyards. Development time is expressed as $T 1 / 2$ in days (a) Means

Chateau Tahbilk

Fergusons

\begin{tabular}{|c|c|c|c|c|c|c|}
\hline \multirow[b]{2}{*}{ Temp. $\left({ }^{\circ} \mathrm{C}\right)$} & \multicolumn{6}{|c|}{ Adh genotype } \\
\hline & $F F$ & $F S$ & $S S$ & $F F$ & $F S$ & $S S$ \\
\hline 20 & $14 \cdot 42 \pm 0 \cdot 17$ & $14 \cdot 23 \pm 0 \cdot 17$ & $14 \cdot 36 \pm 0 \cdot 25$ & $13 \cdot 71 \pm 0 \cdot 10$ & $13 \cdot 75 \pm 0.06$ & $13 \cdot 88 \pm 0 \cdot 24$ \\
\hline 25 & $9 \cdot 77 \pm 0 \cdot 13$ & $9 \cdot 75 \pm 0 \cdot 10$ & $9 \cdot 81 \pm 0 \cdot 10$ & $9 \cdot 51 \pm 0 \cdot 18$ & $9 \cdot 47 \pm 0 \cdot 18$ & $9 \cdot 48 \pm 0 \cdot 21$ \\
\hline 29 & $7 \cdot 88 \pm 0 \cdot 11$ & $7 \cdot 83 \pm 0.06$ & $7 \cdot 89 \pm 0 \cdot 10$ & $7.73 \pm 0.07$ & $7 \cdot 74 \pm 0.04$ & $7 \cdot 81 \pm 0 \cdot 17$ \\
\hline
\end{tabular}

(b) ANOVA

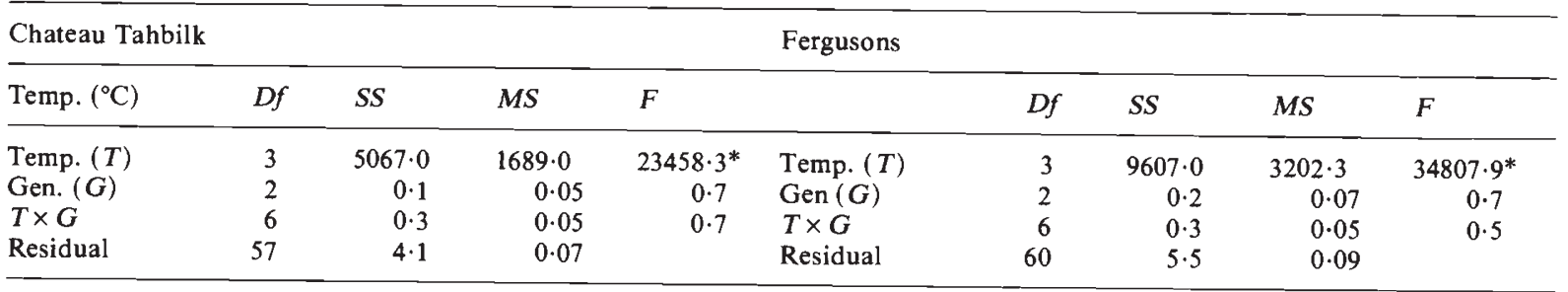

$* p<0.005$.

(b) Mating abilities

In this experiment the unmated genotypic proportions were not manipulated. Further, mating ability differences between $A d h$ genotypes can only be detected by comparisons between observed values and expected values based upon the unmated genotypic proportions if all flies do not mate. Table 7 gives for each sex, replicate and temperature, the number of flies of each $A d h$ genotype in the unmated populations, together with the genotypes of the flies which mated. The $A d h F$ allele frequencies among the unmated flies of each sex, based upon pooled replicates, are also given. It is clear that fewer flies mated at $15^{\circ} \mathrm{C}$ compared with the other temperatures and that all the flies did not mate. However there was one replicate (replicate
2 at $20^{\circ} \mathrm{C}$ and $25^{\circ} \mathrm{C}$ respectively) where almost all the flies mated.

Comparisons between the observed numbers of flies of each $A d h$ genotype which mated and the expected numbers based upon the unmated genotypic proportions for pooled replicates indicated no significant differences for the females at each temperature $\left(15^{\circ} \mathrm{C}, \chi_{2}^{2}=0.33 ; 20^{\circ} \mathrm{C}, \chi_{2}^{2}=\right.$ $0.66 ; 25^{\circ} \mathrm{C}, \chi_{2}^{2}=0.22 ; 29^{\circ} \mathrm{C}, \chi_{2}^{2}=0 \cdot 12$ ). Exclusion of replicate 2 at $20^{\circ} \mathrm{C}$ and $25^{\circ} \mathrm{C}$ did not change this result $\left(20^{\circ} \mathrm{C}, \chi_{2}^{2}=0 \cdot 13 ; 25^{\circ} \mathrm{C}, x_{2}^{2}=0 \cdot 32\right)$. For the males there was a significant deficiency of heterozygotes at $15^{\circ} \mathrm{C}\left(15^{\circ} \mathrm{C}, \chi_{2}^{2}=6.28 p<0.05\right.$; $20^{\circ} \mathrm{C}, \chi_{2}^{2}=0.66 ; 25^{\circ} \mathrm{C}, \chi_{2}^{2}=0.10 ; 29^{\circ} \mathrm{C}, \chi_{2}^{2}=2 \cdot 62$ ). This result was inconsistent with the laboratory strains and the Chateau Tahbilk studies. Again, 
Table 7 (a) Field derived flies-the mating abilities of $A d h$ genotypes. The number of flies of each $A d h$ genotype which mated at each temperature are shown for all replicates and each sex. Also given are the numbers of flies at each Adh genotype which were present in the unmated populations

$O$-observed number which mated

$U$-number in the unmated populations

\begin{tabular}{|c|c|c|c|c|c|c|c|c|c|c|}
\hline \multirow[b]{2}{*}{ Temp. $\left({ }^{\circ} \mathrm{C}\right)$} & \multirow[b]{2}{*}{ Replicate } & \multicolumn{5}{|c|}{ Female genotype } & \multicolumn{4}{|c|}{ Male genotype } \\
\hline & & & $F F$ & $F S$ & $S S$ & Total & $F F$ & $F S$ & $S S$ & Total \\
\hline \multirow[t]{6}{*}{15} & \multirow[t]{2}{*}{1} & $O$ & 7 & 5 & 1 & 13 & 11 & 1 & 1 & 13 \\
\hline & & $U$ & 19 & 10 & 1 & 30 & 18 & 11 & 1 & 30 \\
\hline & \multirow[t]{2}{*}{2} & $O$ & 9 & 5 & 1 & 15 & 10 & 2 & 3 & 15 \\
\hline & & $U$ & 18 & 10 & 1 & 29 & 16 & 11 & 3 & 30 \\
\hline & \multirow[t]{2}{*}{3} & $O$ & 11 & 5 & 1 & 17 & 8 & 8 & 1 & 17 \\
\hline & & $U$ & 14 & 13 & 3 & 30 & 17 & 10 & 1 & 28 \\
\hline \multirow[t]{6}{*}{20} & \multirow[t]{2}{*}{1} & $O$ & 15 & 5 & 1 & 21 & 8 & 8 & 5 & 21 \\
\hline & & $U$ & 20 & 7 & 3 & 30 & 12 & 11 & 7 & 30 \\
\hline & \multirow[t]{2}{*}{2} & $O$ & 15 & 13 & 1 & 29 & 15 & 10 & 4 & 29 \\
\hline & & $U$ & 15 & 14 & 1 & 30 & 15 & 11 & 4 & 30 \\
\hline & \multirow[t]{2}{*}{3} & $O$ & 13 & 10 & 2 & 25 & 13 & 10 & 2 & 25 \\
\hline & & $U$ & 14 & 12 & 3 & 29 & 15 & 12 & 3 & 30 \\
\hline \multirow[t]{6}{*}{25} & \multirow[t]{2}{*}{1} & $O$ & 14 & 11 & 0 & 25 & 4 & 19 & 2 & 25 \\
\hline & & $U$ & 16 & 14 & 0 & 30 & 9 & 19 & 2 & 30 \\
\hline & \multirow[t]{2}{*}{2} & $O$ & 12 & 5 & 1 & 18 & 10 & 7 & 1 & 18 \\
\hline & & $U$ & 18 & 9 & 1 & 28 & 11 & 16 & 1 & 28 \\
\hline & \multirow[t]{2}{*}{3} & $O$ & 16 & 10 & 3 & 29 & 15 & 12 & 2 & 29 \\
\hline & & $U$ & 17 & 10 & 3 & 30 & 15 & 12 & 3 & 30 \\
\hline \multirow[t]{6}{*}{29} & \multirow[t]{2}{*}{1} & $O$ & 12 & 9 & 2 & 23 & 14 & 8 & 1 & 23 \\
\hline & & $U$ & 16 & 12 & 2 & 30 & 16 & 9 & 5 & 30 \\
\hline & \multirow[t]{2}{*}{2} & $O$ & 13 & 9 & 3 & 25 & 14 & 11 & 0 & 25 \\
\hline & & $U$ & 16 & 11 & 3 & 30 & 19 & 11 & 0 & 30 \\
\hline & \multirow[t]{2}{*}{3} & $O$ & 10 & 10 & 0 & 20 & 11 & 8 & 1 & 20 \\
\hline & & $U$ & 14 & 15 & 1 & 30 & 17 & 11 & 2 & 30 \\
\hline
\end{tabular}

(b) AdhF allele frequency among unmated flies, based upon pooled replicates.

\begin{tabular}{lll}
\hline & males & females \\
\hline $15^{\circ} \mathrm{C}$ & 0.76 & 0.76 \\
$20^{\circ} \mathrm{C}$ & 0.74 & 0.66 \\
$25^{\circ} \mathrm{C}$ & 0.77 & 0.66 \\
$29^{\circ} \mathrm{C}$ & 0.72 & 0.75 \\
mean & 0.75 & 0.71 \\
\hline
\end{tabular}

exclusion of replicate 2 at $20^{\circ} \mathrm{C}$ and $25^{\circ} \mathrm{C}$ did not change this result $\left(20^{\circ} \mathrm{C}, \chi_{2}^{2}=0.73 ; 25^{\circ} \mathrm{C}, \chi_{2}^{2}=\right.$ $0 \cdot 20)$.

(c) Field derived discrete generation populations The results for the discrete generation population experiment using flies derived directly from the field are shown in fig. 6 . The $A d h F$ allele frequencies are given for all populations and generations sampled at each temperature with means. These data have been assessed by $t$-tests between the initial and final generations sampled. The initial mean $A d h F$ allele frequencies for the Chateau Tahbilk and Fergusons populations were $0.59 \pm$ 0.05 and $0.69 \pm 0.06$ respectively. There was no evidence for significant $A d h F$ allele frequency change at all temperatures for both the Chateau Tahbilk and Fergusons populations. Comparisons between the observed numbers of $A d h$ genotypes and expected numbers assuming Hardy-Weinberg proportions indicated that only one value was significant-the founding generation, population $B$, derived from Chateau Tahbilk $\left(\chi_{1}^{2}=11.99, p<\right.$ $0.05)$ where there was a deficiency of heterozygotes. Thus, the above results were not consistent with the laboratory derived populations, the Chateau Tahbilk data, the clinal data discussed in the Introduction, and the experiments of van Delden et al. (1978) and Wilson et al. (1982). 

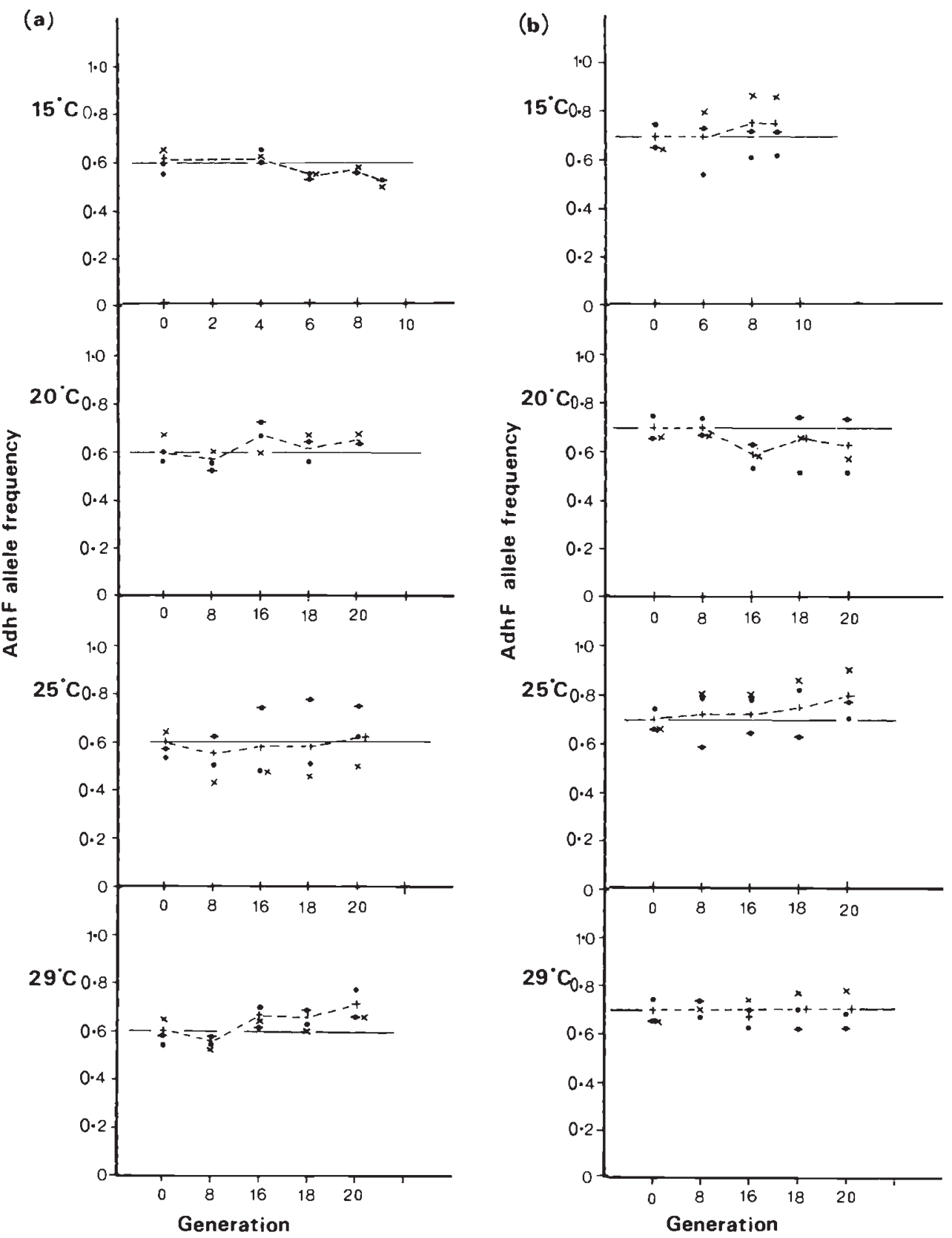

- Population A

- Population B

$\times$ Population C

+ Mean value

Figure 6 Discrete generation population cage experiments conducted with field derived flies: The change in $A d h^{F}$ allele frequency observed in populations derived from Chateau Tahbilk (a) and Fergusons (b) and maintained at $15^{\circ} \mathrm{C}, 20^{\circ} \mathrm{C}, 25^{\circ} \mathrm{C}$, and $29^{\circ} \mathrm{C}$ Values are given for each population and generation sampled. 


\section{DISCUSSION}

\section{Fitness and temperature}

The results show significant fitness differences between $A d h$ genotypes for laboratory adapted but not field derived flies and larvae, so that the $A d h$ allele frequency changes in the laboratory populations cannot be interpreted as being directly attributable to the Adh locus. It should be noted that hidden genetic variation exists at the $A d h$ locus (Gibson et al. 1980, 1981 b; Wilks et al., 1980; Chambers et al., 1981; van Delden, 1982) and that this may have contributed to the results. Whilst acknowledging this, the population cage results indicate that the genotypic fitness estimates obtained with the laboratory adapted strains may be difficult to relate to natural populations. Thus, whilst significant differences for fitness at single loci may be demonstratable for laboratory adapted strains, their relation to the field may be obscure.

It is important to briefly discuss the significant results for the laboratory adapted strains in the context of the literature. van Delden and Kamping (1979) found that the development time of $A d h F F$ was slightly more rapid than $A d h F S$ and both were faster than $A d h S S$ in standard food at $25^{\circ} \mathrm{C}$. Their results are in general agreement with those presented here. The fitness data presented also indicate that high genotypic survival was associated with rapid genotypic development time (tables 1 and 2). Giesel and Zettler (1980) found a positive genetic correlation between survival and development time in $D$. melanogaster. These authors used highly inbred lines and hybrids where fitness depends upon the number and severity of recessive deleterious alleles fixed by inbreeding. Positive correlations among fitness components are expected for such alleles (Rose and Charlesworth $1981 a, b)$. The positive genetic correlations among fitness components found here for $A d h$ could result from the use of isofemale strains which had been in laboratory culture for 18 months. Finally, the egg to adult survival and development time data are not consistent with other studies (van Delden, 1982) since the $A d h$ allele and presumably alleles of other loci obtained from the female parent appear to determine the result (tables 1 and 2). This observation suggests that, in certain circumstances, the earlier functional activity of the female haploid genome (Wright and Shaw, 1969; Korochkin, 1981) can be reflected in fitness.

Considering mating ability, the majority of significant differences were associated with males (table 3 ) in accord with the Chateau Tahbilk data (see Introduction) and the general conclusion that male mating speed is a most important fitness component in Drosophila (Parsons, 1974). Further, in accord with the Chateau Tahbilk data, each significant departure from random mating involved heterozygote excess which was especially evident at $29^{\circ} \mathrm{C}$, suggesting an extreme environment effect.

The population cage results (figs. 1 to 6 ) are not generally consistent with the literature (see Introduction) which indicates that $A d h S$ allele frequency decreases with distance from the equator and with increasing altitude. An increase in $A d h S$ allele frequency would therefore be expected in populations cultured at the relatively higher temperatures of $25^{\circ} \mathrm{C}$ and $29^{\circ} \mathrm{C}$, but was not found at any temperature (table 4 ). The Chateau Tahbilk studies of McKechnie and McKenzie (1983), indicate that the $A d h S$ allele frequency decreases with temperature increase in a range from $8^{\circ} \mathrm{C}$ to $22^{\circ} \mathrm{C}$. The comparable temperatures in this study were $15^{\circ} \mathrm{C}$ and $20^{\circ} \mathrm{C}$ and $A d h S$ allele frequency significantly decreased for all initial allele frequencies at $15^{\circ} \mathrm{C}$ and for $0.5 \mathrm{~F}$ at $20^{\circ} \mathrm{C}$. Thus, there is a degree of consistency between the laboratory populations and the field populations from which the former were derived. However, the obvious absence in the laboratory populations of a return to the $A d h F$ equilibrium usually observed at Chateau Tahbilk (approximately 0.65 ) is not expected since this equilibrium is generally conserved there (McKechnie and McKenzie, 1983; McKenzie et al., in preparation).

Further van Delden et al. (1978) found that their laboratory populations, initiated at different allele frequencies, showed a convergence of frequencies on regular food at $25^{\circ} \mathrm{C}$. The equilibrium values were similar to those in the base populations. The authors interpreted their results as some form of balancing selection. In their populations cultured at $29^{\circ} \mathrm{C}$ a lower equilibrium frequency of $A d h F$ was observed and this is in accord with the clinal data. Wilson et al. (1982) detected weak selective differences between the $A d h F$ and $A d h S$ alleles in laboratory populations cultured at $22^{\circ} \mathrm{C}$ on standard laboratory food. The fitness estimates obtained indicated that the $A d h F$ allele would eventually become fixed and this was not in agreement with the populations from which the experimental lines were extracted. In the population experiments presented here there was only one case of $A d h F$ allele fixation-in the populations cultured at $25^{\circ} \mathrm{C}$ for an initial frequency of $0.75 \mathrm{~F}$. This result was not confirmed when the $20^{\circ} \mathrm{C}$ $0.75 F$ populations were subcultured to $25^{\circ} \mathrm{C}$ at generation 13 and maintained for a further 20 generations. 
As previously noted, the presence of environmental levels of ethanol together with temperature variation may be more important for $A d h$ than is assumed here. Several laboratory experiments indicate that $A d h F$ reaches higher equilibrium frequencies in ethanol supplemented food compared with unsupplemented controls (van Delden, 1982). However, these results were generally obtained with populations which had been in laboratory culture for at least a year (Oakeshott, Gibson and Wilson, 1984). There is a similarity between the results obtained here-an increase in $A d h F$ allele frequency for all populations where allele frequency changes-and the above. This suggests that whilst ethanol presence appears important, laboratory culture may be more so. Finally, the population data do not provide consistent evidence for heterozygote advantage despite this general result for the estimated fitness components.

The initial assumption that the relatively extreme temperatures of $15^{\circ} \mathrm{C}$ and $29^{\circ} \mathrm{C}$ are sufficiently stressful in regard to increased levels of expressed genetic variation for fitness, appears to be satisfied for the $A d h$ locus in the laboratory adapted strains. Significant allele frequency changes in the populations and genotypic differences for fitness components were frequently associated with these temperatures. As discussed below, laboratory culture itself can be regarded as an imposed environmental stress. The lack of significant results for the field derived flies and larvae suggests that in this circumstance these temperatures were not sufficiently stressful. For populations closely related to nature, the use of relatively greater stresses of the type likely to be experienced in nature is probably required.

\section{Domestication}

The contrast between the laboratory adapted strains and the field derived flies and larvae could be due to changes in the genetic architectures of particular fitness traits which have evolved under a particular selection regime in nature. The switch into the laboratory presumably alters the selection regime, although it is difficult to specify the nature of the changes. Apparently the effect of genetic background, in the form of fitness differences, was enhanced for the laboratory adapted flies and larvae. In addition, laboratory culture can be regarded as an imposed environmental stress, being an artificial situation and so a form of domestication. Thus, the contrast could be due to increased genetic variation for fitness as expressed in extreme environments (Parsons, 1983) where the extreme environment arises because of transfer from field to laboratory.

The contrast between the laboratory adapted strains and the field derived flies and larvae may provide a model for what may occur during domestication generally. The results presented indicate that phenotypic selection as a consequence of selection and/or environmentally induced effects upon phenotypic development precedes genetic change in $D$. melanogaster populations transferred from the field to the laboratory. The fitness component studies for the field derived flies and larvae indicated that whilst phenotypic fitness varied, there was no associated variation at the genotypic level for the $A d h$ locus since there were no significant $A d h$ allele frequency changes in the field derived populations. Thus, based upon the results for the $A d h$ locus it appeared that primary phenotypic selection was operating in these populations.

This situation contrasts with the laboratory adapted strains where phenotypic and genotypic variability in fitness were detected for the $A d h$ locus in most populations. Thus, based upon the $A d h$ locus, after 18 months in laboratory culture, phenotypic variability has become associated with genotypic variability. However, it must be noted that the functional relationships between a change in $A d h$ genotype and phenotypic fitness differences remain unclear. Since no common $A d h F$ allele frequency was approached in the populations derived from the laboratory adapted strains (figs. 1 to 5), considerable phenotypic and genotypic differentiation may be occurring in these populations. However, the possibility of genetic drift in the form of founder effects cannot be excluded in this case. The above discussion therefore accords with Price (1984) who suggests that the process of domestication involves some combination of genetic changes occurring over generations and environmentally induced events re-occurring during each generation. Finally, an increase in genetic and phenotypic variability characterizes domestic populations (Price, 1984) and this is supported by the results presented.

Survival and development time appear to be more affected than mating ability in the domestication of $D$. melanogaster since the former traits varied more between the laboratory and field populations. This also suggests that there is more additive genetic variance for survival and development time compared with mating ability, with mating ability being apparently subject to intense directional selection irrespective of habitat (Parsons, 1974). Thus, given the importance of mating ability 
as a fitness component for D. melanogaster it follows that its potential for change in the domestication of $D$. melanogaster should be limited.

\section{An organismic approach to gene frequency changes}

Finally, we commenced with the assumption that the gene is the determiner of phenotypic fitness variation. Experiments based upon this approach cannot provide a complete understanding of phenotypic fitness in natural populations because of the effects of multiple loci, interactions between loci, linkage relationships and interactions between genotype and environment. Further, this approach which frequently begins with an electrophoretic locus and searches, a posteriori, for correlations of adaptive significance may confound causation with correlation (Hoffmann et al., 1984). In this regard, a variable which is correlated with an allozyme genotype is likely to be a component of the overall phenotype. Hence, an a priori approach via electrophoretic loci could not provide a complete analysis of this phenotype (Ziolo and Parsons, 1982). The above limitations are demonstrated in the experiments presented here since genotypic variation in fitness at the $A d h$ locus was not relatable to temperature related phenotypic fitness variation.

The above approach contrasts with an a priori one commencing at the phenotypic level in the assessment of the genetic basis of fitness variation. In the context of this paper where temperature was used as a variable to demonstrate selection upon a single locus, assessment of the genetic basis of ecological phenotypes such as resistance to temperature extremes and dessication resistance is relevant. These phenotypes are demonstratively adaptive and relatable to evolutionary change at the population level (Parsons, 1983). Such phenotypes tend to be quantitative at the observational level and their genetic analysis may commence with simpler aspects of the biometrical and polygenic approaches to quantitative inheritance (Thompson and Thoday, 1979). For example, in genetically well known organisms such as $D$. melanogaster, genetic activity can be localised to chromosomes or regions of a chromosome, based upon the assessment of extreme isofemale strains. derived from a population (Parsons, 1980) or by selection procedures. Therefore, clarification of the role of the $A d h$ locus in temperature related fitness variation in $D$. melanogaster could begin with assessment of the genetic bases of the above phenotypes in a number of Drosophila species, in particular contrasting colonising and non- colonising species. Because of the ecological extremes to which colonising species are subjected, genotypic and phenotypic differences are magnified and are therefore simpler to elucidate compared with more optimal conditions (Parsons, 1984). This approach could be extended to $D$. melanogaster strains derived from a variety of geographical regions, contrasting under stress those derived from relatively extreme and relatively optimal climates. Such an approach may more precisely resolve the relationship of the $A d h$ locus with fitness in natural populations of Drosophila than is the situation as presently deduced from many recent discussions in the literature.

Acknowledgements We are grateful to Dr John Oakeshott for helpful discussions.

\section{REFERENCES}

CHAMBERS, G. K., LAVER, W. G., CAMPBELL, S. AND GIBSON, J. B. 1981. Structural analysis of an electrophoretically cryptic alcohol dehydrogenase variant from an Australian population Drosophila melanogaster. Proc. Natl. Acad. Sci., USA, 78, 3103-3107.

CLARKE, B. 1975. The contribution of ecological genetics to evolutionary theory: Detecting the direct effects of natural selection on particular polymorphic loci. Genetics, 79, 101113.

DAVID, J. R. 1982. Latitudinal variability of Drosophila melanogaster: allozyme frequencies divergence between European and Afrotropical populations. Biochem. Genet., $20,747-761$.

DAWkins, R. 1981. The Extended Phenotype: The Gene as the Unit of Selection. W. H. Freeman, Oxford.

FRANKLIN, I. R. 1981. An analysis of temporal variation at isozyme loci in Drosophila melanogaster. Gibson, J. B. and Oakeshott, J. G. (eds.) In Genetic Studies of Drosophila Populations, Australian National University Press, Canberra, pp. 217-236.

GIBSON, J. B., CHAMBERS, G. K., WILKS, A. V. AND OAKESHOTT, J. G. 1980. An electrophoretically cryptic alcohol dehydrogenase variant in Drosophila melanogaster. I. Activity ratios, thermostability, genetic localization and comparison with two other thermostable variants. Aust. J. Biol. Sci., 33, 479-489.

GIBSON, J. B., MAY, T. W. AND WILKS, A. V. $1981 a$. Genetic variation at the alcohol dehydrogenase locus in Drosophila melanogaster in relation to environmental variation: ethanol levels in breeding sites and allozyme frequencies. Oecologia, 51, 191-198.

GIBSON, J. B., WILKS, A. V. AND CHAMBERS, G. K. $1981 b$ Population variation in functional properties of alcohol dehydrogenase in Drosophila melanogaster, Gibson, J. B. and Oakeshott, J. G. (eds.), In Genetic Studies of Drosophila populations. Australian National University Press, Canberra, Australia, pp. 251-267.

GIESEL, J. T. AND ZETTLER, E. E. 1980. Genetic correlations of life historical parameters and certain fitness indices in Drosophila melanogaster: $r_{m}, r_{s}$, diet breadth. Oecologia, 47, 299-302.

HICKEY, D. A. AND MCLEAN, M. D. 1980. Selection for ethanol tolerance and $A d h$ allozymes in natural populations of Drosophila melanogaster. Genet. Res., 36, 11-15. 
HOFFMANN, A. A., NIELSEN, K. M. AND PARSONS, P. A. 1984. Spatial variation of biochemical and ecological phenotypes in Drosophila: Electrophoretic and quantitative variation. Devel. Genet., 4, 439.

HOLMES, R. S., MOXON, L. N. AND PARSONS, P. A. 1980. Genetic variability of alcohol dehydrogenase among Australian Drosophila species: correlation of $A D H$ biochemical phenotype with ethanol resource utilization. J. Exp. Zool., 214, 199-204.

JOHNSON, F. M. AND SCHAFFER, H. E. 1973. Isozyme variability in species of the genus Drosophila VII. Genotype-environment relationships in populations of $D$. melanogaster from the Eastern United States. Biochem. Genet., 10, 149163.

JOHNSON, G. B. 1979. Genetic polymorphism among enzyme loci. Scandalios, J. G. (ed.) In Physiological Genetics, Academic Press, New York, pp. 239-273.

KNOPPIEN, P., POT, W. AND VAN DELDEN, W. 1980. Effects of rearing conditions and age on the difference in mating success between alcohol dehydrogenase genotypes of Drosophila melanogaster. Genetica, 51, 197-202.

KOROCHKIN, L. I. 1981. Gene Interactions in Development. Springer-Verlag, Berlin.

MCKECHNIE, S. W. AND GEER, B. W. 1984. Regulation of alcohol dehydrogenase in Drosophila melanogaster by dietary alcohol and carbohydrate. Insect Biochem, 14, 231242.

MCKECHNIE, S. W. AND MCKENZIE, J. A. 1983. Polymorphism of alcohol dehydrogenase $(A d h)$ in a winery cellar population of Drosophila melanogaster: Gene frequency association with temperature and genotypic differences in progeny production. Evolution, 37, 850-853.

MCKECHNIE, S. W. AND MORGAN, P. 1982. Alcohol dehydrogenase polymorphism of Drosophila melanogaster: Aspects of alcohol and temperature variation in the larval environment. Aust. J. Biol. Sci., 35, 85-93.

MCKENZIE, J. A. 1978. The effect of developmental temperature on population flexibility in Drosophila melanogaster and D. simulans. Aust. J. Zool., 26, 105-112.

MCKENZIE, J. A. AND FEGENT, J. C. 1980. Mating patterns of virgin and inseminated Drosophila melanogaster of different alcohol dehydrogenase (Adh) genotypes. Experientia, 36, 1160-1161.

MCKENZIE, J. A. AND McKECHNIE, S. W. 1978. Ethanol tolerance and the $A d h$ polymorphism in a natural population of Drosophila melanogaster. Nature, 272, 75-76.

MCKENZIE, J. A. AND MCKECHNIE, S. W. 1981. The alcohol dehydrogenase polymorphism in a vineyard cellar population of Drosophila melanogaster. Gibson, J. B. and Oakeshott, J. G. (eds.) In Genetic Studies of Drosophila Populations, Australian National University Press, Canberra, pp. 201-215.

MCKENZIE, J. A., MCKECHNIE, S. W. AND BATTERHAM, P. Perturbation of gene frequencies in a natural population of Drosophila melanogaster: Evidence for selection at the Adh locus, In preparation.

MCKENZIE, J. A. AND PARSONS, P. A. 1974. Microdifferentiation in a natural population of Drosophila melanogaster to alcohol in the environment. Genetics, 77, 385-394.

MALPICA, J. M. AND VASSALlo, J. M. 1980. A test for the selective origin of environmentally correlated allozyme patterns. Nature, 286, 407-408.

MIDDLETON, R. J. AND KACSER, H. 1983. Enzyme variation, metabolic flux and fitness: alcohol dehydrogenase in Drosophila melanogaster. Genetics, 105, 633-650.

OAKESHOTT, J. G., GIBSON, J. B., ANDERSON, P. R. AND CHAMP, A. 1980. Opposing modes of selection on the alcohol dehydrogenase locus in Drosophila melanogaster. Aust. J. Biol. Sci., 33, 105-114.
OAKESHOTT, J. G., GIBSON, J. B., ANDERSON, P. R., KNIBB, W. R., ANDERSON, D. G. AND CHAMBERS, G. K. 1982. Alcohol dehydrogenase and glycerol-3-phosphate dehydrogenase clines in Drosophila melanogaster on different continents. Evolution, 36, 86-96.

OAKESHOTT, J. G., GIBSON, J. B. AND WILSON, S. R. 1984. Selective effects of the genetic background and ethanol on the alcohol dehydrogenase polymorphism in Drosophila melanogaster. Heredity, (In press).

OAKESHOTT, J. G., MCKECHNIE, S. W. AND CHAMBERS, G. K. 1984. Population genetics of the metabolically related Adh, Gpdh and Tpi polymorphisms in Drosophila melanogaster: I. Geographic variation in Gpdh and Tpi allele frequencies in different continents. Genetica, 63, 21-29.

PARSONS, P. A. 1974. Male mating speed as a component of fitness in Drosophila. Behavior Genetics, 4, 395-403.

PARSONS, P. A. 1980. Isofemale strains and evolutionary strategies in natural populations. Evol. Biol., 13, 175-217.

PARSONS, P. A. 1983. The Evolutionary Biology of Colonizing Species, Cambridge University Press, New York.

PARSONS, P. A. 1984. Colonizing Species: A probe into evolution via the organism. Endeavour, 8, 108-112.

POT, W., VAN DELDEN, W. AND KRUIJT, J. P. 1980. Genotypic differences in mating success and the maintenance of the alcohol dehydrogenase polymorphism in Drosophila melanogaster: No evidence for overdominance or rare genotype mating advantage. Behav. Genet., 10, 43-58.

PRICE, E. O. 1984. Behavioral aspects of animal domestication. Quart. Rev. Biol., 59, 1-32.

PROUT, T. $1971 a$. The relation between fitness components and population prediction in Drosophila. I: The estimation of fitness components. Genetics, 68, 127-149.

PROUT, T. $1971 \mathrm{~b}$. The relation between fitness components and population prediction in Drosophila. II. Population prediction. Genetics, 68, 151-167.

ROSE, M. R. AND CHARLESWORTH, B. 1981 $a$. Genetics of life history in Drosophila melanogaster. I. Sib analysis of adult females. Genetics, 97, 173-186.

ROSE, M. R. AND CHARLESWORTH, B. $1981 b$. Genetics of life history in Drosophila melanogaster. II. Exploratory selection experiments. Genetics, 97, 187-196.

THOMPSON, J. N. JR. AND THODAY, J. M. 1979. Quantitative Genetic Variation. Academic Press, New York.

VAN DELDEN, w. 1982. The alcohol dehydrogenase polymorphism in Drosophila melanogaster. Evol. Biol., 15, 187222.

VAN DELDEN, W., BOEREMA, A. C. AND KAMPING, A. 1978. The alcohol dehydrogenase polymorphism in populations of Drosophila melanogaster. I. Selection in different environments. Genetics, 90, 161-191.

VAN DELDEN, W. AND KAMPING, A. 1979. The alcohol dehydrogenase polymorphism in populations of Drosophila melanogaster. III. Differences in development times. Genet. Res., 33, 15-27.

WILKS, A. V., GIBSON, J. B., OAKESHOTT, J. G. AND CHAMBERS, G. K. 1980. An electrophoretically cryptic alcohol dehydrogenase variant in Drosophila melanogaster. II. Postelectrophoresis heat treatment screening of natural populations. Aust. J. Biol. Sci., 33, 575-585.

WILSON, S. R., OAKESHOTT, J. G., GIBSON, J. B. AND ANDERSON, P. R. 1982. Measuring selection coefficients affecting the alcohol dehydrogenase polymorphism in Drosophila melanogaster. Genetics, 100, 113-126.

WRIGHT, D. A. AND SHAW, C. R. 1969. Time of expression of genes controlling specific enzymes in Drosophila embryos. Biochem. Genet., 4, 385-394.

ZIOLO, L. K. AND PARSONS, P. A. 1982. Ethanol tolerance, alcohol dehydrogenase activity and Adh allozymes in Drosophila melanogaster. Genetica, 57, 231-237. 